Western University Scholarship@Western

2016

\title{
Licensing Parents in International Contract Pregnancies
}

Andrew Botterell

Western University, abottere@uwo.ca

Carolyn McLeod

Western University, cmcleod2@uwo.ca

Follow this and additional works at: https://ir.lib.uwo.ca/lawpub

Part of the Family Law Commons

Citation of this paper:

Botterell, A. and C. McLeod. “Licensing Parents in International Contract Pregnancies," Journal of Applied Philosophy 33:2 (2016): 178-196. 


\title{
Licensing Parents in International Contract Pregnancies*
}

By Andrew Botterell and Carolyn McLeod

*Submitted version; please cite only the published version

\begin{abstract}
The Hague Conference on Private International Law currently has a Parentage/Surrogacy Project, which evaluates the legal status of children in cross-border situations, including situations involving international contract pregnancy (or 'surrogacy'). Should a convention (or other legal instrument) focusing on international contract pregnancy emerge from this project, it will need to be consistent with the Hague Convention on Intercountry Adoption. The latter convention prohibits adoptions unless, among other things, "the competent authorities of the receiving State have determined that the prospective adoptive parents are eligible and suited to adopt" (Article 5a). Included in it, therefore, is a parental vetting or licensing requirement. In our view, a similar requirement must also appear in any Hague Convention on international contract pregnancy if the two conventions are to be ethically consistent with one another. In particular, there should be a licensing requirement in such a convention for at least some of the prospective parents in contract pregnancy arrangements. We consider several arguments against this conclusion, and argue that none of them is successful.
\end{abstract}




\section{Introduction}

The issue of whether people should be licensed to become parents - the issue, that is, of whether the state should restrict the ability of individuals to become parents unless or until they reveal some competency to be a parent-has generated significant

controversy. ${ }^{1}$ Currently, some parents are licensed: namely, adoptive parents. ${ }^{2}$ They have to undergo a home study and, sometimes, mandatory parenting classes before adopting a child. While some philosophers (e.g., Hugh LaFollette) contend that such requirements should exist for all parents, we have argued for a more nuanced position: that so long as such requirements are imposed on adoptive parents, they should be imposed on all or some subset of non-adoptive parents as well. ${ }^{3}$ In other words, we have claimed that what we call the "status quo on parental licensing" — according to which licensing should occur with adoption (more specifically, with non-relative, non-step-parent adoption), ${ }^{4}$ but not with biological reproduction — is morally unjustified.

The issue of whether licensing should occur for a larger subset of parents than just adoptive parents is relevant to current debates about international law and policy on international contract pregnancy (or 'surrogacy', as it is often called). The Hague Conference on Private International Law (the Hague Conference) has recently decided to convene an Experts' Group to explore the feasibility of continuing work on its Parentage/Surrogacy Project, which concerns the legal status of children in cross-border situations, including international contract pregnancy arrangements. ${ }^{5}$ Although this group is merely a working group - there is no commitment on the part of the Hague Conference at this time to develop a convention on international contract pregnancy - it will nonetheless need to consider the extent to which any such convention should be informed 
by the Hague Conference's Convention on Adoption (i.e., the 1993 Convention on Protection of Children and Co-operation in Respect of Intercountry Adoption). ${ }^{6}$ The latter convention includes a parental licensing requirement: Article 5a states that "[a]n adoption within the scope of the Convention shall take place only if the competent authorities of the receiving State have determined that the prospective adoptive parents are eligible and suited to adopt." Some commentators feel that a similar articleconcerning the parental fitness of people who want to become parents through contract pregnancy ${ }^{7}$ - should appear in any Convention on this practice, ${ }^{8}$ while others strongly disagree. ${ }^{9}$ We argue in this paper that the Hague Conference cannot consistently demand parental licensing for adoption but not for contract pregnancy, or at least not for some people who wish to become parents through this practice. In other words, so long as it has Article 5a in its Convention on Adoption, it ought to have an article on licensing in any convention that it develops on contract pregnancy.

It is an open question to what degree the two conventions would have to be similar for them to be ethically consistent with one another. We distinguish between a weak and a strong version of the claim that there should be licensing for individuals who engage in contract pregnancy so long as there is licensing for individuals who seek to adopt children. The strong version of the claim holds that all individuals who pursue contract pregnancy should be licensed, while the weak version holds only that some of these individuals—namely, those who will not be genetically related to any resulting child — should be licensed. Although we argue here only in support of the weak claim, our arguments leave open the possibility that the strong claim may be true nonetheless 
(and moreover, arguments we have made elsewhere suggest that this claim is indeed true).

In what follows, we present a number of arguments that people have given or could give for the conclusion that while parental licensing is appropriate in the case of adoption, it is never appropriate in the case of contract pregnancy. Either directly or indirectly, these arguments support the status quo on parental licensing, which again involves no licensing for people who engage in (assisted or unassisted) reproduction. We explain why each of these arguments fails. In so doing, we draw on our previous work on parental licensing, but also extend the scope of that work by claiming that arguments in favour of the status quo are especially weak when applied to people who seek to become parents through contract pregnancy.

Reasons given against the imposition of a licensing requirement on people who pursue contract pregnancy sometimes focus on the fact that this practice involves biological reproduction. We begin with such arguments and then turn to those that have nothing to do with reproduction.

\section{Arguments that Concern Biological Reproduction}

"Surrogacy belongs to the world of reproduction rather than adoption", according to Natalie Gamble, a solicitor in the UK whose firm specializes in "fertility and parenting law" and helps clients become parents through contract pregnancy. ${ }^{10}$ In a recent article, Gamble insists that the prior vetting of people who wish to become parents in this

manner is inappropriate. ${ }^{11}$ Among her reasons are the following: that such a requirement would be unfair, given that people who are fertile and who reproduce do not have to 
“jump through hoops" to become parents ${ }^{12}$; that it would be "an interference with

parents" right to procreate"13; and that "parents conceiving through surrogacy are no more likely to be unsuitable than fertile parents"-they are no more likely, in other words, to harm children — and so vetting is unnecessary in their case. ${ }^{14}$ We call these arguments the Fairness Argument, the Right to Reproduce Argument, and the Harm to Children Argument, respectively, and we evaluate each in turn. Along the way—and in particular when discussing the Right to Reproduce Argument—we question Gamble's suggestion that with contract pregnancy, members of the commissioning couple always reproduce, rather than simply initiate reproduction. (And to be clear, we interpret 'biological reproduction' broadly such that it occurs whenever one acquires a biological connection to a child produced through genetics, gestation, or both.) Contract pregnancy is indeed a form of assisted reproduction, but the people who reproduce through it are not always those who commission the pregnancy.

\section{(i) The Fairness Argument}

Let us begin with the Fairness Argument. It aims to show that it would be unfair to license people who pursue contract pregnancy specifically, or who use assisted reproductive technologies (ARTs) more generally, because people who reproduce through sexual intercourse are not subject to such interference by the state. The main purpose of this argument is therefore not to endorse the status quo on parental licensing, but rather to reject on grounds of fairness the suggestion that licensing should occur with any form of assisted reproduction. Nonetheless, the argument supports the status quo 
indirectly, because it fails to question whether licensing for adoption is itself inappropriate or possibly unfair.

The Fairness Argument emphasizes similarities between assisted and unassisted reproduction and concludes that, because vetting is not required in the case of the latter, it should not be required in the case of the former either. But this argument overlooks the obvious fact that in addition to being similar to unassisted reproduction, assisted reproduction is also similar in other respects to adoption and may be similar to it in ways that are relevant to whether licensing should occur. For example, with both assisted reproduction and adoption, one becomes a parent only with assistance from others, which makes licensing more feasible than it is with unassisted reproduction ${ }^{15}$ : licensing can be a condition on receiving the appropriate assistance, whereas it is hardly feasible to make it a condition on having unprotected sexual intercourse. The similarity with regards to feasibility is relevant to whether licensing should occur if, in practice, parents can only be licensed when it is feasible to do so. Thus, in light of such a similarity between assisted reproduction and adoption, one could argue that there should be licensing with both practices, or that so long as the status quo - and more importantly in the present context, the Hague Convention on Adoption - requires parental licensing for adoption, a similar requirement should exist for assisted reproduction and should appear in any Hague Convention on contract pregnancy.

The main problem, then, with the Fairness Argument is that it begs the question, "Why, when it comes to assessing whether parental licensing is warranted, is assisted reproduction taken to be relevantly similar to unassisted reproduction but relevantly dissimilar to adoption?" This question is crucial given that in certain respects, assisted 
reproduction can be more similar to adoption than to unassisted reproduction; and if that is true, then licensing those who want to become parents through adoption or assisted reproduction may be justified. $^{16}$

To see how contract pregnancy, in particular, resembles or can resemble adoption, consider the fact that contract pregnancy often involves the use of donor gametes. In many cases, one set of gametes is donated (usually oocytes ${ }^{17}$ ) and in some cases, both sets are donated. With the former type of case, only one prospective parent will be biologically related to any resulting child, while with the latter type, neither prospective parent will have this sort of connection to the child. Both of these types of contract pregnancy are like adoption then, in that they involve people becoming parents to children to whom they have no biological tie. But according to one argument in support of the status quo on parental licensing, the absence of such a tie is precisely what justifies licensing in the case of adoption. (See the Harm to Children Argument I below.) Thus, in some instances, contract pregnancy resembles adoption in a way that might make parental licensing appropriate in both cases.

Of course, contract pregnancy can also resemble unassisted reproduction in ways that may be relevant to licensing. For example, one might think that with contract pregnancy, as with unassisted (or other forms of assisted) reproduction, prospective parents exercise a right to reproduce, and that it is impermissible for the state to interfere unduly with the exercise of this right. Or one might think that with no form of reproduction — not even contract pregnancy_-does parental responsibility get transferred between parties (i.e., between birth parents or guardians and soon-to-be social parents), and so there is nothing for the state to oversee or regulate. Below, we consider these 
possibilities, among others, for how contract pregnancy might be relevantly similar to unassisted or other forms of reproduction, but dissimilar to adoption. Our claim in each case is that either the purported dissimilarities to adoption are merely apparent or they are not relevant to whether the prospective parents should be licensed. These conclusions are significant for the Fairness Argument because they show that one cannot simply put assisted and unassisted reproduction together in a separate category from adoption when determining whether parental licensing is justified.

To be clear, we are not arguing that because some contract pregnancies are similar to adoptions, we should treat all contract pregnancies like adoptions. The point is rather that an uncritical appeal to the concept of fairness cannot establish that parental licensing is always inappropriate in the case of contract pregnancy. At best, the Fairness Argument, as it is applied to contract pregnancy, is inconclusive. It neglects to show why, given that people who reproduce via sexual intercourse are unlicensed, it would be unfair to license people who use ARTs, but fair to continue licensing people who choose to adopt children. The explanation cannot simply be that only the first two ways of becoming a parent- - via sexual intercourse or through the use of ARTs - involve biological reproduction, since the mere fact that someone reproduces cannot determine whether that individual should be licensed. Thus, for all that the Fairness Argument says, fairness might demand that parental vetting be a requirement with contract pregnancy and be included in any convention governing this practice.

Note, finally, that one could respond to the Fairness Argument by insisting that adoptive parents should not be licensed either. Such a response might indeed be legitimate (although we have our doubts). ${ }^{18}$ Yet if the intent of the Hague Conference is 
to fashion a convention on contract pregnancy that is ethically consistent with the Convention on Adoption - a document that already requires the licensing of prospective adoptive parents - then the two conventions must treat relevantly similar prospective parents in similar ways. And in our opinion, this involves requiring that at least some people who pursue parenthood through contract pregnancy be vetted, just as individuals who choose adoption are vetted.

\section{(ii) The Right to Reproduce Argument}

Thus, the Fairness Argument does not provide compelling reasons for likening contract pregnancy, or other forms of assisted reproduction, to unassisted reproduction rather than to adoption in debates about parental licensing. But are there reasons for thinking that the relevant comparison should be to unassisted reproduction rather than to adoption? In other words, should one accept that the status quo on parental licensing is justified? One important argument in support of this state of affairs, which we mentioned above in passing, relies on the so-called "right to reproduce". According to this argument, whereas licensing would violate the right to reproduce of prospective biological parents, it violates no such right in the case of prospective adoptive parents, given that the latter clearly do not exercise a right to reproduce when becoming parents. ${ }^{19}$ This difference could explain why it makes sense to treat people who use ARTs in the same way as other individuals who reproduce without assistance, and to distinguish them from people who pursue adoption. On this view, licensing members of the former group is inappropriate because it interferes with their right to reproduce. 
In previous work, we have questioned whether people do in fact have a moral right to reproduce. Here, we discuss some of our skepticism with respect to this right, but also contend that one need not doubt the existence of such a right in order to defeat the Right to Reproduce Argument as it applies to contract pregnancy. The reason is that some prospective parents in contract pregnancies could not be exercising a right to reproduce. And if that is true, then even if this right could explain why individuals who engage in unassisted reproduction should be exempt from parental licensing, it could not explain why all individuals who pursue contract pregnancy should be similarly exempt.

To spell out our view in more detail, note that prospective parents who will not be biologically related to any child born through contract pregnancy do not reproduce biologically through this practice. These are individuals whose gametes are not used in conceiving the pregnancy and who therefore will have no genetic connection to any resulting child. (And of course, neither prospective parent will have a gestational connection either.) It follows that not all individuals who seek to become parents through contract pregnancy exercise a right to reproduce in doing so. When people use ARTs to create children to whom they have no biological connection — not even a biological connection established during pregnancy—-they themselves do not reproduce. It will not do to say that without their contributions, a new life would not be created, and thus, that they themselves are reproducing. For the same can be said about the contributions of IVF clinicians, and surely they do not reproduce when they perform IVF successfully. There is therefore a gap between playing an essential role in biological reproduction and exercising a right to reproduce. ${ }^{20}$ Since many individuals who commission pregnancies 
from women do the former but not the latter, a right to reproduce could not protect them from being vetted as prospective parents.

Granted, some people who have children via contract pregnancy do reproduce: namely, those whose gametes are used in the creation of these children. Surely a right to reproduce would preclude them from being licensed as parents. Or would it? In a previous paper on the right to reproduce and parental licensing, we question whether this right could protect people who, in fact, reproduce from having to undergo parental licensing, given that it is not clear the right even exists. ${ }^{21}$ In that paper, we distinguish between a right to reproduce and a right to become a parent. ${ }^{22}$ And we indicate that while the reasons people can have for wanting to become a parent can be very good, ${ }^{23}$ the same is not true of the reasons people typically give for wanting to become a biological parent, especially a genetic parent (i.e., the only kind of biological parent that one could become by commissioning a pregnancy). Various critiques exist in the literature of the desire to be genetically linked to one's children. ${ }^{24}$ Due to limitations of space, we can only summarize these arguments here (and, therefore, will not make strong conclusions based on them) ${ }^{25}$ In brief, they suggest that this desire is often based on a view of genetics that is naïve (e.g., that family resemblances are primarily genetic) or that exaggerates the importance of genetic similarities among family members; on a problematic conception of the parent-child relationship (i.e., that a child is not truly one's own unless one is genetically related to him or her); or on false beliefs about adoption (e.g., that people tend not to love adopted children as much as they do their "own" children). Views of this sort find no support within the science of genetics, ${ }^{26}$ moral analyses of the parent-child relationship, or empirical evidence about adoption and adopted children. They therefore 
should be rejected. However, without them, a right to reproduce — understood here as a right to have genetic children ${ }^{27}$ - has very little basis to it. ${ }^{28}$ We are therefore skeptical of this right and doubt that it could justify unfettered access to contract pregnancy for people who seek to become genetic parents through this practice.

Our view, then, is that the Right to Reproduce Argument, as it is applied to contract pregnancy, suffers from two weaknesses. First, it assumes that individuals who choose to become parents through contract pregnancy reproduce, which is not universally true. Second, it is only successful if the reproductive element of this practice is morally relevant to whether people who pursue it as a means to become a parent should undergo parental licensing. But such a claim is doubtful, in our opinion. What is more likely relevant is that these people, like prospective adoptive parents, simply want to become parents (and are exercising a putative right to do so). In short, we think the prospects are dim for any attempts to argue that a right to reproduce can justify licensing for prospective adoptive parents but not for people who want to become parents via contract pregnancy.

Still, we recognize that we have not shown fully here why a right to reproduce could not be a barrier to licensing for people who in fact reproduce through contract pregnancy. Thus, one might be left thinking that these people should not be licensed on the grounds that they are exercising such a right. Moreover, one might go further and insist that their partners should not be licensed either, even when their partners will have no genetic relation to any resulting child. One could argue that such cases resemble stepparent adoption — where the prospective non-biological parent will be parenting with a biological parent — and most jurisdictions do not require stepparents to go through the 
rigours of a normal adoption to adopt their children. To respond to this objection, notice that this element of the status quo finds no support in the argument we are now considering, according to which the licensing of adoptive parents is appropriate because they do not exercise a right to reproduce. It follows from this argument that licensing should occur with stepparent adoptions — for after all, stepparents do not exercise a right to reproduce either when they seek to become parents of their partner's biological child. Thus, proponents of the Right to Reproduce Argument cannot appeal to the status quo to establish that where only one member of a commissioning couple reproduces through contract pregnancy, both members should be spared the trials of licensing.

To conclude this section, we have argued that the Right to Reproduce Argument cannot protect people from licensing who do not reproduce through contract pregnancy. Even more, the argument supports the inclusion of a licensing requirement for these individuals in any Hague convention on contract pregnancy. Consequently, our weak claim — that so long as adopted parents are licensed, some individuals who pursue contract pregnancy should also be licensed—is bolstered by this argument. But perhaps a different argument, one that focuses on the risk of harm to children, would lead to a different conclusion.

\section{(iii) The Harm to Children Argument I}

All children, whether adopted or not, are at risk of being harmed by bad parenting. This much is clear. But some assume that adopted children are at greater risk of harm from bad or incompetent parenting than are non-adopted children. According to this line of thought, licensing prospective adoptive parents is important because it reduces this risk. 
On the other hand, licensing other prospective parents, including people who have children via contract pregnancy, is unnecessary. The reason is that the children of these parents are at no greater risk of harm than children born to "fertile parents", as Gamble puts it.

Two explanations are typically given for why the risk of harm from bad parenting is greater in the case of adoption. One explanation is that the lack of a biological connection between parent and child in an adoption increases the possibility of harm to the child. A different explanation rests on the following two claims: that many adopted children have what we call, perhaps misleadingly, "special needs", and that without ensuring that prospective adoptive parents have special training to meet these needs, the risk of bad parenting is heightened in this context. We focus on the first explanation in this section, and then turn our attention to the second explanation in the next section.

Why would the lack of a biological connection between parent and child increase the likelihood of abuse or neglect in the parent-child relationship? For some, the answer to this question is obvious: parents who are not biologically related to their childrenthrough genetics or gestation — have no "natural affection" for them and so are more likely to harm them. ${ }^{29}$ In the past, we have given this view more attention than it probably deserves by indicating how little support it receives within the empirical literature on parental abuse and neglect (and also within literature on the effectiveness of parental licensing in reducing the risk for parental abuse or neglect by adoptive parents).${ }^{30}$ Here, let us simply add that empirical studies on bonding between mothers and their young children shows that bonding is just as strong for adoptive mothers as it is for so-called "natural mothers". ${ }^{31}$ 
Thus, an argument in favour of licensing adoptive parents that focuses on harm to children and a lack of biological relatedness is most likely empirically invalid. But more importantly for our purposes, even if a lack of biological relatedness increased the risk of harm to children from bad parenting, this fact could not show that licensing should always occur with adoption but should never occur with contract pregnancy. The reason, of course, is that some prospective parents who pursue contract pregnancy—namely those whose gametes are not used in this process - will themselves have no biological tie to any resulting child. According to the Harm to Children argument that focuses on biological relatedness (which we call the Harm to Children Argument I), these parentsalong with adoptive parents and other non-biological parents—should be subject to licensing.

In short, the Harm to Children Argument I is weak in general, and is especially weak when applied to contract pregnancy, given that children created this way often have no biological tie, of any kind, to one parent. Consequently, the lack of a biological connection cannot constitute a moral difference sufficient to distinguish these parents from adoptive parents where parental vetting is at issue. The problem, again, is that in important respects, many individuals who seek to become parents through contract pregnancy are in the same boat, biologically speaking, as prospective adoptive parents. Thus, even if we accept the Harm to Children Argument I—despite how little empirical support there is for it—we should insist that many individuals who pursue contract pregnancy should be licensed. 
We are not done with the Harm to Children Argument, however. For a different formulation of this argument exists, one that concerns neither biological relatedness nor biological reproduction, but the particular needs of particular children. We turn to it now.

\section{Arguments that Do Not Concern Biological Reproduction}

The previous arguments against licensing individuals who pursue contract pregnancy as a way to become a parent have focused on the reproductive aspects of this practice, and have sought to distinguish contract pregnancy from adoption on the grounds that while the former involves biological reproduction, the latter does not. In response to these arguments, we have claimed that the presence or absence of biological reproduction cannot establish that licensing individuals who seek to become parents through contract pregnancy is never justified. But there are also arguments against parental licensing for people who pursue contract pregnancy that do not focus on the reproductive element of this practice. Arguments of this sort include the version of the Harm to Children Argument that focuses on the needs of adopted children and what we call the Transfer of Responsibility Argument.

(i) The Harm to Children Argument II

An alternative argument based on harm to children that supports licensing prospective adoptive parents but not people who wish to become parents through contract pregnancy focuses not on the lack of a biological tie but rather on the allegedly special needs of adopted children and the harm that parents can cause if they are not competent to meet these needs. Again, this argument draws a contrast between adopted children and 
children created via contract pregnancy: the former have special needs while the latter do not. It is the presence of such needs, according to the argument, that justifies parental licensing in the case of adoptive parents. We will call this the Harm to Children Argument II.

Before analyzing this argument, let us make three observations. First, if special needs are to do the work that the argument requires of them, then those needs must meet two conditions: (i) they must apply to many or all adopted children; and (ii) they must not apply to many or all children created through contract pregnancy. Otherwise, the argument will not be able to draw the necessary distinction between adoption and contract pregnancy.

Second, among the special needs that could exist among many or all adopted children are the following ${ }^{32}$ : needs that arise because of "adversity in early childhood", such as abuse, neglect, abandonment, or other forms of deprivation or trauma ${ }^{33}$; and more controversially, the alleged need to know one's genetic relatives. This second type of need is usually justified in terms of damage to the identity formation of the child: not knowing one's genetic relatives supposedly means that one will not be able to answer "the pivotal question, 'Who am I'?"34 The central claim in the Harm to Children Argument II is that adopted children often have one or both of these types of needsneeds that put them at risk of harm from bad parenting — whereas children who are conceived via contract pregnancy lack these special needs or, alternatively, are less likely to be put at risk of harm by bad parenting even if they have these needs.

Third, as noted above, the term 'special needs' may be somewhat misleading. ${ }^{35}$ This term is usually understood narrowly to include only those needs that are associated 
with significant behavioural, physical, social, or emotional problems. But it could also be understood broadly to include any need that is unique or special to a particular individual or group of individuals. (Thus, the need that somebody with significant mobility issues has for a power wheelchair counts as a special need in the narrow sense, while a Muslim's need for halal meat counts as a special need in the broad sense.) Here, we use both senses of the term 'special needs'. For example, we, and others, invoke the narrow sense when referring to psychological and emotional needs among adopted children that arise because of adversity in early life. But we invoke the broad sense when characterizing the alleged need to know one's genetic relatives as a "special need". Children who possess the latter sort of need do not necessarily have behavourial or emotional problems. Still, the thought is that they may develop such problems if this need goes unmet; that is, they may acquire special needs in the narrow sense. Hence, regardless of whether one is talking about the need to know genetic relatives or needs associated with early adversity, claims about adopted children having these needs appeal to a narrow understanding of special needs. They suggest that these children have significant behavioural or emotional problems or are at serious risk of developing such problems (and these claims contribute, as a result, to the stigmatization of these children). We have chosen the language of "special needs" in part because it allows us to convey this fact.

Let us return now to the argument that adopted children have special needs that children created by contract pregnancy lack, and that this alleged fact explains why adoptive parents, and adoptive parents alone, should be licensed. There are at least two ways to criticize this argument. First, one could challenge the claim that special needs 
exist among adopted children but not among children created via contract pregnancy (if indeed adopted children are properly characterized as having special needs at all). And second, one could argue that the presence of special needs cannot be what explains why adoptive parents are subject to parental licensing. We pursue both strategies here.

Let us begin with the claim that adopted children are unique in having special needs compared to children who are born via contract pregnancy. The first point to consider is whether adopted children do indeed have special needs. Many people would probably say that they do (i.e., have special needs in the narrow sense), on the grounds that these children tend to exhibit more behavioural or emotional problems than children who are not adopted. However, research on the psychological well-being of adopted children simply does not support this view. Instead, it shows that "[ $\mathrm{t}]$ he vast majority of children who are adopted are well within the normal range of well-being and show behavioural patterns that are similar to their non-adopted peers". ${ }^{36}$ Thus, assuming that non-adopted children are, on average, well adjusted psychologically, the same is true of adopted children.

This research does not, however, rule out the possibility that many adopted children have special needs at the time of their adoption. Many of them may have special needs at that time, for example, because of adversity they have faced up to that point, needs that in most cases disappear sometime after they are adopted. Their immersion in a family that has been selected for them might counteract the effects of their early experiences. Indeed, a recent review of studies indicates that many children make a "remarkable recovery" from early adversity when they are adopted. ${ }^{37}$ In addition, even if adopted children always have a special need for some sort of connection to biological 
family, this need could be met in most adoptions because of the relatively recent openness with adoption (i.e., openness to children knowing of or having contact with their birth family). In sum, although it is important to emphasize that the "vast majority" of adopted children do just fine, this fact may have more to do with the support they get from their adoptive families than with the absence of special needs among them before they are adopted.

The second point we want to make is that to the extent that a need for information about genetic relatives is genuine, this need exists among many children who are born as a result of a contract pregnancy and is therefore not restricted to adopted children. When children are created through contract pregnancies that involve the use of donor gametes, they too are at risk of estrangement from their genetic relatives (a risk that is surely heightened with international contract pregnancy and among children who were created using both donor sperm and donor oocytes). This consideration counts against the following claims: (i) that prospective adoptive parents need to be vetted to ensure that they have the ability to parent children who will not be raised by their biological family, although the same is not true of parents of children created through contract pregnancy ${ }^{38}$; and (ii) that adopted children are alone in having special needs compared to children created through contract pregnancy.

As noted above, the view that children have special needs as a result of not knowing their genetic relatives is controversial. This view raises a host of questions, not the least of which is how much information about genetic relatives is necessary in order to overcome or mitigate those special needs. Are basic autobiographical details enough? ${ }^{39}$ Is a whole life story necessary? Would the child have to have ongoing, face- 
to-face contact with biological relatives to form a healthy identity? ${ }^{40}$ The more information that one deems necessary, the less convincing one's theory about identity formation will be, because it will contradict the empirical evidence about how welladjusted adopted children tend to be. For example, many of these well-adjusted children, including those in open adoptions, lack face-to-face contact with biological family, and surely most have only partial stories about who their genetic relatives are or were. ${ }^{41}$

Adopted children could be unique after all in having special needs compared to children who are born through contract pregnancy if it turns out to be false that knowledge of one's genetic relatives is important for one's well-being. In that case, adopted children would likely be alone in having special needs associated with adversity in early life. On the other hand, it is important to consider whether children born through contract pregnancy might have special needs that adopted children lack. Some say that many of these children are at risk of being perceived and of perceiving themselves as products of the exploitation of poor and vulnerable women. ${ }^{42}$ Alternatively, they could be at risk of harm simply from knowing that a woman gestated and gave birth to them for money and then promptly gave them up.

Thus, it is at best unclear whether parental licensing could be warranted for adoption but not for contract pregnancy on the grounds that adoption alone involves parenting children with special needs. We have spent considerable effort showing this much because - in our experience as adoptive parents - it is common for people to express the view that adopted children have special needs and are difficult to parent for this reason, while assuming the opposite about non-adopted children. 
Let us turn now to the claim that the presence of special needs explains why adoptive parents are subject to parental licensing in the first place. This proposition is doubtful simply because many children who are raised by their biological parents themselves have special needs (i.e., those associated with significant behavioural, emotional or other problems) and yet their parents are not subject to licensing. Thus, in our view, a concern about meeting special needs could not be what motivates the current system of licensing. ${ }^{43}$ The Harm to Children Argument II therefore fails to justify the claim that there should be licensing for adoption but not for contract pregnancy. Let us now evaluate one final argument in favour of this position.

(ii) The Transfer of Responsibility Argument

A different argument in support of licensing for prospective parents who pursue adoption, but not for those who choose contract pregnancy, focuses on parental responsibility. The argument rests on two distinct claims: first, that there is a fundamental difference between the way in which parental responsibility is acquired in the case of adoption, compared to contract pregnancy and other forms of reproduction; and second, that this difference implies that only adoptive parents should be subject to parental licensing. The animating idea, in brief, is this. Before an adoption occurs there exists a child for whom someone — the state or an actual person—is responsible. During an adoption, this responsibility is transferred to someone else, namely the child's adoptive parent(s). The reason why parental licensing is required in the case of adoption is to ensure that this transfer occurs in a morally serious manner, something that can happen only if the party or parties relinquishing responsibility for the child can 
reasonably expect that the child's future will be good (or at least good enough).

Licensing provides such assurance to the child's pre-adoptive guardians and is justified for this reason. We call this the Transfer of Responsibility argument. ${ }^{44}$

Although this argument is deployed primarily to support the status quo on parental licensing, it can also be used to argue that no licensing should occur specifically in the context of contract pregnancy. Such reasoning would proceed as follows. Prior to the formation of a pregnancy contract there is no child for whom someone is responsible. Indeed, only after the contract has been performed does a child exist. Consequently, the idea that there is a transfer of responsibility for a child with contract pregnancy must be rejected, and with it the idea that there should be licensing for people who pursue this practice.

To respond, we think that the Transfer of Responsibility Argument is invalid: the presence or absence of a transfer of responsibility for a child cannot be what justifies the status quo on parental licensing, nor can it support the claim that licensing should never occur in the context of contract pregnancy. ${ }^{45}$ We hold his view for the following reason: if transfers of parental responsibility demand a level of moral seriousness that justifies a parental licensing requirement, then surely acquisitions of parental responsibility ought to be treated in a similarly serious manner. But given that in a contract pregnancy, the commissioning couple clearly acquires parental responsibility for a child (i.e., the child who is gestated by the contract pregnant woman), it stands to reason that such individuals should be licensed if the normative principle underlying the Transfer of Responsibility Argument — the principle about moral seriousness - is true. In short, if we accept this 
principle, and regardless of whether contract pregnancy involves a transfer of parental responsibility, we should agree that there should be parental licensing in this context.

But let us focus here not on the validity (or structure) of the Transfer of Responsibility Argument, but rather on what it suggests about contract pregnancy: namely, that this practice involves no transfer of responsibility. We reject this claim. Indeed, we contend that a transfer of responsibility does occur with contract pregnancy: the contract pregnant woman transfers some responsibility for the child to whom she gives birth to the commissioning couple. ${ }^{46}$ Thus, again, if one agrees that licensing adoptive parents is justified because it ensures that responsibility for a child is transferred properly, then one ought to accept that the prospective parents of any child created through contract pregnancy should be licensed.

Two aspects of this issue deserve further comment, however. The first concerns an apparent asymmetry between adoption and contract pregnancy that would justify the imposition of a licensing requirement on adoptive parents alone. The second concerns the role of the state in imposing this requirement. Turning to the first point, notice that in discussing adoption, we used the term 'parental responsibility.' And one might object that in cases of contract pregnancy, this is precisely what is missing: the contract pregnant woman, whatever else her relation to the child she gestates, is not the child's parent; she is (merely) a "gestator." Thus, even if something is transferred from her to the child's intentional parents, it is not parental responsibility that is transferred, and the analogy breaks down.

To respond to this argument, it is worth stating to begin with that parental responsibility might be precisely what is transferred in such cases. Given the murkiness 
of the moral waters here, it is difficult to conclude that the contract pregnant woman is not a parent to the child she gestates and therefore could not transfer parental responsibility for this child to the commissioning couple. Gestation could ground parenthood $^{47}$; and if it does so, then a child that a woman gestates for others is partly her child, regardless of whether she is genetically related to the child.

But set this issue about gestation and parenthood aside. The more important consideration, in our view, is the following. Even if the responsibility the contract pregnant woman has toward the future child she gestates is not properly characterized as parental, she nevertheless has at least some care-taking responsibility for this child during the pregnancy, a responsibility that she transfers to other people once the child is born. Broadly speaking, her responsibility extends to the physical well-being of the future child (e.g., to its nourishment and physical safety), while the commissioning couple has responsibility throughout for other aspects of the child's well-being (including those that concern the child's future well-being, such as where s/he will live, how s/he will be educated, etc.). In addition, if nothing else, the contract pregnant woman's responsibility should give rise to an interest in her to ensure that the individuals who will parent the child she gestates will love and care for that child. Assuming all of that is true, in the context of contract pregnancy, there is a transfer of responsibility-more specifically, for a future child's physical well-being — and the person from whom the responsibility is transferred has an interest in knowing that this child's prospective parents will be good ones. It follows, according to the Transfer of Responsibility Argument, that there should be parental licensing in this context. 
One could still offer the following counter-response, however: rather than being transferred between the different parties, the responsibility of the contract pregnant woman might simply be delegated to her by the commissioning couple when she conceives and gestates "their child". And if that were true, then the commissioning couple would retain all responsibility for the future child during the pregnancy, while having the pregnant woman carry out some of this responsibility. In short, according to this counter-response, because no responsibility of any kind is transferred from the commissioning couple to the contract pregnant woman—responsibility is merely delegated - it follows from the Transfer of Responsibility Argument that parental licensing for commissioning couples is unjustified. ${ }^{48}$

We reject the above characterization, however, because we believe that the only person who could, or should, have ultimate responsibility for the physical well-being of a future child in pregnancy is the pregnant woman herself. The reason is that others could only exercise this responsibility by confining or controlling the pregnant woman to a degree that would violate her autonomy or undermine her dignity. To illustrate, compare the relationship between the contract pregnant woman and the commissioning couple to the relationship between a set of parents and a babysitter who agrees to care for their child for an evening (or a weekend, or a week). If the parents were to learn that the babysitter was ignoring his duties, or was performing those duties in a negligent fashion, they could remedy the situation by removing the child from the babysitter's care, terminating the agreement, and sending the babysitter home. Ultimate responsibility for the child would remain with the parents throughout. 
But the case of a contract pregnant woman seems very different. To see why, suppose the following: that the commissioning couple does retain ultimate responsibility for the future child's physical well-being and merely delegates this responsibility to the contract pregnant woman in accordance with the terms of the pregnancy contract; that the commissioning couple learns that the contract pregnant woman is not meeting the terms of the contract—because, for example, she is eating poorly; and that she cannot be persuaded to do otherwise. In such a situation, it seems that the only recourse available to the commissioning couple would be to limit the freedom of the contract pregnant woman severely, and in the case of her not eating properly, to coerce her to eat or even forcefeed her. But such action, it seems to us, fails to respect her autonomy and dignity. If, in other words, the commissioning couple did retain ultimate responsibility for the future child's physical well-being, then they would be permitted - indeed obligated - to do the impermissible. And this suggests that in order for the pregnancy contract to be valid, the contract pregnant woman must have ultimate responsibility for the physical well-being of the future child for the duration of the contract. The commissioning couple cannot have this responsibility — which is not to say that they could not be parents to the child, given that it is possible to be a parent without having or exercising parental responsibility (as is the case for parents who have lost custody of their child).

To be clear, the argument here is not that all pregnancy contracts are morally suspect because they inevitably compromise the dignity or autonomy of the contract pregnant woman. To the contrary, we accept that in the absence of coercion or exploitation a woman could freely enter into a valid pregnancy contract. Rather, the argument is that a pregnancy contract could be valid only if the contract pregnant woman 
assumes some ultimate responsibility for the future child, responsibility that she subsequently transfers to the commissioning couple.

A second aspect of the Transfer of Responsibility Argument concerns the role of the state and the reasons it has for imposing a licensing requirement on prospective parents. In the case of adoptions, the state is clearly involved in the process by which responsibility for the child is transferred from one party to another. The state may actively assume responsibility for the child and then transfer that responsibility to somebody else, as is the case with public domestic adoptions; or the state may oversee the transfer of the child from one responsible party to another and approve it by issuing various legal documents, such as visas or citizenship certificates in the case of international adoptions. In other words, it may be the state's involvement in the transfer of responsibility that justifies it in imposing a licensing requirement on prospective adoptive parents. If, however, the state has no involvement in overseeing contract pregnancies, then an important difference may exist between any obligations it incurs in connection with contract pregnancy and its obligations with respect to adoption.

We would resist this argument, however, on the grounds that the state is involved in the transfer of the care of a child who is created through contract pregnancy, especially in the international variety of this practice. Through the operation of its legal mechanisms, the state grants parental rights to the commissioning couple and, in the case of international contract pregnancy, statehood to the child. ${ }^{49}$ Because such actions are normatively significant, both for the child and for the child's parents, they ought to occur in a morally serious manner, which is precisely what parental vetting seeks to ensure according to the Transfer of Responsibility Argument. 
In short, it is hard to see a moral difference between adoption and contract pregnancy when it comes to the transfer of responsibility for a child. In both cases, there is an individual who has some, if not all, responsibility for the well-being of a child, and who relinquishes this responsibility to somebody else who assumes parental responsibility for him or her. And in both cases, the state is involved in this transfer of responsibility. Consequently, if parental licensing is justified in the case of adoption on the grounds outlined in the Transfer of Responsibility Argument, then it must be justified in the case of contract pregnancy as well. The same considerations apply to both practices.

Many people find the Transfer of Responsibility Argument compelling. ${ }^{50}$ But to reiterate, we are not among them. In our view, the moral principle underlying this argument is not a narrow principle involving transfers of responsibility, but rather the broader principle that acquisitions of parental responsibility must be undertaken in a morally serious manner. Thus, even if our remarks concerning transfers of responsibility in the context of contract pregnancy are misguided, the Transfer of Responsibility Argument would still fail to block a parental vetting requirement for individuals who seek to become parents through contract pregnancy.

\section{Conclusion}

To conclude, we have presented what we take to be the best arguments one could give for why a parental licensing requirement should be absent from a Hague convention on international contract pregnancy, despite the fact that such a requirement appears in the Convention on Adoption. Moreover, we take ourselves to have shown that none of these 
arguments succeeds. While our analysis of many of them indicates that all prospective parents in contract pregnancy arrangements should be subject to some sort of licensing requirement so long as prospective adoptive parents are subject to the same, our assessment here of some of these arguments, however - in particular, the Right to Reproduce Argument-showed only that prospective parents who do not reproduce through contract pregnancy should have to undergo licensing. A (so-called) right to reproduce could protect any other prospective parents from having to do the same. Thus, we have proven only the weak claim that some individuals who pursue contract pregnancy should be licensed, again so long as adoptive parents are licensed. Our general conclusion with respect to the Hague Conference is therefore as follows: to be ethically consistent with the Convention on Adoption, any convention on international contract pregnancy should include an article that requires the receiving country to determine that at least some of the prospective parents of children born through contract pregnancy will most likely fulfill these children's needs.

Notice, however, that the weak claim that some individuals who pursue contract pregnancy should be licensed may bleed into the stronger claim that all or most of these individuals should be licensed. Once one endorses the first claim, in other words, one may have to accept the second as well. Whether that is true may depend, moreover, on how one understands parental licensing. For example, if one has in mind a traditional home study_which involves an intimate look at one's household, financial status, relationships with others, etcetera - then it may simply be impractical to license one prospective parent (i.e., the one who will not be genetically related to any resulting child), but not the other. In that case, one should license both (or neither, although in 
licensing neither, one may show insufficient concern for children's well-being ${ }^{51}$ ). But if one thinks that licensing should simply involve a mandatory parenting course for example, then one member of a couple could probably be licensed on his or her own. In short, considerations about what is feasible and about what form parental licensing should take will shape what the Hague Conference could do around parental licensing for contract pregnancy. We have not discussed these matters here, but rather have shown simply that there are no good moral reasons (as opposed to purely practical reasons) for excluding a licensing requirement from a Hague convention on contract pregnancy while maintaining the current requirement in the Hague Convention on Adoption. Ethical consistency demands that the former convention impose some kind of licensing on some prospective parents who pursue international contract pregnancy.

Lastly, there must be other ways in which the two conventions would have to resemble one another in order to be ethically consistent with one another, and we discuss some of these elsewhere. ${ }^{52}$ In this paper, we have focused only on the issue of parental licensing. Beyond what it recommends on this subject, however, this paper has implications for the larger project of ensuring that no ethical inconsistencies exist between the two documents. Our discussion reveals that one commonly cited difference between contract pregnancy and adoption - that the one involves biological reproduction while the other does not—is less significant than many commentators assume it is. ${ }^{53}$ Even though biological reproduction occurs with contract pregnancy, the parents of children born in this way do not necessarily have a genetic tie to them, did not give birth to them, and in arranging to have those children conceived, do not always exercise a (socalled) right to reproduce. In other words, the situation of many of these parents is in 
many respects indistinguishable from that of adoptive parents. Thus, it would be difficult for the Hague Conference to justify the unequal treatment of these two groups of parents on the grounds that adoption, unlike contract pregnancy, does not involve biological reproduction.

\section{NOTES}

${ }^{1}$ The classic paper is Hugh LaFollette, 'Licensing Parents', Philosophy and Public Affairs, 9, 2 (1980): 183-197. See also Hugh LaFollette, 'Licensing Parents Revisited', Journal of Applied Philosophy, 27, 4 (2010): 327-343; Peggy Tittle, ed., Should Parents Be Licensed? (Amherst, MA: Preometheus Books, 2004); Daniel Engster, 'The Place of Parenting Within a Liberal Theory of Justice', Social Theory and Practice, 36, 2 (2010): 233-62; and Daniel Weinstock and Jurgen De Wispelaere, 'Licensing Parents to Protect our Children?' Ethics and Social Welfare, 6, 2 (2012): 195-205. The term 'licensing' is interchangeable with 'vetting' (i.e., parental vetting). Both terms refer to restrictions on people's freedom to parent a child that the state imposes on them even though they may have never mistreated children.

${ }^{2}$ This is not to say that all adoptive parents are licensed. Step-parent and so-called "relative" adoptions are exempt from this requirement. For discussion, see Carolyn McLeod and Andrew Botterell, "Not for the Faint of Heart': Assessing the Status Quo on Adoption and Parental Licensing' in F. Baylis and C. McLeod (eds.) Family-Making: Contemporary Ethical Challenges (Oxford: Oxford University Press, 2014), p. 154. 
${ }^{3}$ McLeod and Botterell ibid; and Botterell and McLeod, 'Can a Right to Reproduce Justify the Status Quo on Parental Licensing?' Forthcoming in R. Vernon, S. Brennan, and S. Hannan (eds.) Permissible Progeny (New York: Oxford University Press).

${ }^{4}$ Unless specified otherwise, when we refer to adoption, we mean non-relative, nonstepparent adoption. The brief description we have given here of the status quo on parental licensing leaves out various complexities with it, including the fact that some gay or lesbian couples who engage in assisted reproduction must undergo licensing. For a more detailed description of the status quo, see McLeod and Botterell op. cit. note 2, pp. $154-155$.

${ }^{5}$ See paragraph 5 of the document 'Conclusions \& Recommendations Adopted by the Council', which emerged from the Council on General Affairs and Policy of the Hague Conference on Private International Law (24-26 March 2015). Available at http://www.hcch.net/upload/wop/gap2015concl_en.pdf. For additional background information, see 'The Parentage/Surrogacy Project: An Updating Note’ (February 2015), available at http://www.hcch.net/upload/wop/gap2015pd03a_en.pdf.

6 'A Preliminary Report on the Issues Arising from International Surrogacy Arrangements.' Available at http://www.hcch.net/upload/wop/gap2012pd10en.pdf. (Permanent Bureau, Hague Conference on Private International Law, 2012). ${ }^{7}$ For ease of exposition, we refer simply to contract pregnancy rather than international contract pregnancy unless we need to emphasize the international dimension of this practice. We do the same for adoption, as opposed to international adoption.

Moreover, although our concern here is with international contract pregnancy and adoption - and in particular, with the way in which the Hague Conference ought to 
regulate these practices - much of what we say is also relevant to the domestic versions of these practices and to their regulation at a domestic level.

${ }^{8}$ Katarina Trimmings and Paul Beaumont, 'International Surrogacy Arrangements: An Urgent Need for Legal Regulation at the International Level', Journal of Private International Law 7, 3 (2011): 627-647.

${ }^{9}$ Natalie Gamble, 'Surrogacy: creating a sensible national and international legal framework', International Family Law, September (2012): 308-311. Available at http://www.nataliegambleassociates.com/assets/assets/Sep $\% 202012 \% 20-020$ IFL $\% 20$ $\% 20$ Surrogacy $\% 20$ creating $\% 20 \mathrm{a} \% 20$ sensible $\% 20$ national $\% 20$ and $\% 20$ international $\% 201$ egal\%20framework.pdf.

${ }^{10}$ See http://www.nataliegambleassociates.co.uk and Gamble op. cit. note 9, p. 311.

${ }^{11}$ Gamble ibid.

12 Ibid., p. 309.

${ }^{13}$ Ibid.

${ }^{14}$ Ibid., p. 311.

${ }^{15}$ See McLeod and Botterell op. cit. note 2, p. 159.

${ }^{16}$ Another plausible alternative, of course, is that no relevant moral differences exist among these three ways of becoming parents, in which case there should be licensing for all parents or for none of them.

${ }^{17}$ See the Council for Responsible Genetics, 'Surrogacy in America', 2010: 1-40 (at 9), available at http://www.councilforresponsiblegenetics.org/blog/post/New-CRG-Reporton-Surrogacy-in-America.aspx. The use of donor oocytes is common because of the frequency with which gay male couples engage in contract pregnancy arrangements and 
presumably also because of the "advanced maternal age" (a medical term) of the woman in many heterosexual couples that access these services.

${ }^{18}$ We believe that at least minimal vetting in the form of police checks should occur for prospective adoptive parents, and for many other prospective parents as well.

${ }^{19}$ Botterell and McLeod op. cit. note 3.

${ }^{20}$ Ibid.

${ }^{21}$ Ibid.

${ }^{22}$ We also distinguish these rights from a right to parent one's biological baby. See Anca Gheaus, 'The Right to Parent One's Biological Baby', Journal of Political Philosophy 20, 4 (2012): 432-455.

${ }^{23}$ See Harry Brighouse and Adam Swift, 'Parents' Rights and the Value of the Family', Ethics 117, 1 (2006): 80-108; and Brighouse and Swift, 'The Goods of Parenting', in F. Baylis and C. McLeod (eds.) Family-Making: Contemporary Ethical Challenges (Oxford: Oxford University Press, 2014): 11-28.

${ }^{24}$ Neil Levy and Mianna Lotz, 'Reproductive Cloning and a (Kind of) Genetic Fallacy', Bioethics 19 (2005): 232-250; Daniel Friedrich, 'A Duty to Adopt?' Journal of Applied Philosophy, 30, 1 (2013): 25-39; Christine Overall, 'What is the Value of Procreation?' in F. Baylis and C. McLeod (eds.) Family-Making: Contemporary Ethical Challenges (Oxford: Oxford University Press, 2014): 89-108; and Tina Rulli, 'Preferring a Genetically-Related Child,' Journal of Moral Philosophy (2014): doi 10.1163/174552434681062.

${ }^{25}$ We also focus on those that concern purely genetic parenthood, that is, parenthood with a genetic but not a gestational connection. Some of the arguments in this literature 
concern the desire to have a genetically related child that oneself or one's partner gives birth to.

${ }^{26}$ On whether the science of genetics supports the view that family resemblances are primarily genetic, see Levy and Lotz, op. cit. note 25, pp. 237-8. They explain that people tend grossly to exaggerate the role that genetic factors, as opposed to social factors, play in determining who we are or who our genetic children will or would be. ${ }^{27}$ One could understand the right more broadly to include not only the right to have genetic children but also the right to gestate those children. However, as implied above, this broader understanding of the right is not relevant to people who pursue contract pregnancy as a way of having children.

${ }^{28}$ To be fair, these reasons in support of a right to reproduce are not exhaustive. For example, some cite religious reasons in support of the claim that some individuals have a right to reproduce. By way of illustration, consider the following passage from the King James Bible: 'And you, be ye fruitful, and multiply; bring forth abundantly in the earth, and multiply therein.' (Genesis 9:7) Here, God is not commanding Noah and his sons to create families, but is rather commanding them to reproduce and repopulate the earth. It is therefore difficult to see how adoption could satisfy God's admonition to the faithful to multiply fruitfully and bring forth abundantly. Alternatively, members of groups that have been subject to eugenics programs or to genocide might themselves assert a right to reproduce that is distinct from a right to become a parent. So, for example, individuals whose extended family perished in the Holocaust, or were killed in the Rwandan genocide, might insist that they have a right to reproduce, because only by reproducing can the wrongs that have been done to them and to their family be mitigated. For some 
discussion of these issues, see McLeod and Botterell op. cit. note 2 and Karey Harwood, 'Bad Habit or Considered Decision? The need for a closer examination of prospective parents' views', International Journal of Feminist Approaches to Bioethics, 7, 1 (2014): 46-50. For objections to the claim that religious reasons can justify a preference for reproduction over adoption, see Christine Overall, op. cit. note 24, p. 21.

${ }^{29}$ See LaFollette 1980, p. 195. He mentions this view but not endorse it.

${ }^{30}$ See McLeod and Botterell op. cit. note 2, pp. 156-157.

${ }^{31}$ See L.M. Singer et al., 'Mother-infant attachment in adoptive families', Child Development, 56, 6 (1985): 1543-1551; J.E. Koepke et al., 'Becoming Parents: Feelings of Adoptive Mothers', Pediatric Nursing, 17, 4 (1991): 333-336; and Judith Daniluk and Joss Hurtig-Mitchell, 'Themes of Hope and Healing: Infertile Couples' Experiences of Adoption', Journal of Counseling and Development, 81, 4 (2003): 389-399. Thanks to Tina Rulli for directing us to this literature.

${ }^{32}$ Excluded, for example, are needs associated with physical or psychological infirmities that have been present since birth.

${ }^{33}$ See Lucy Blake et al., 'The Families of Assisted Reproduction and Adoption', in F. Baylis and C. McLeod (eds.) Family-Making: Contemporary Ethical Challenges (Oxford: Oxford University Press, 2014), p. 75.

${ }^{34}$ Françoise Baylis, 'Transnational Commercial Contract Pregnancy in India' in F. Baylis and C. McLeod (eds.) Family-Making: Contemporary Ethical Challenges (Oxford: Oxford University Press, 2014), p. 277. See also David Velleman, 'Family History', Philosophical Papers, 34, 3 (2005): 357-378. Here, we interpret a right to know one's genetic relatives as being more robust than a right simply to know one's medical history. 
Children who have non-biological parents may indeed have the latter right, while lacking the former right.

35 Thanks to Françoise Baylis for raising this point in conversation with us.

${ }^{36}$ Blake et al. op. cit. note 33, p. 76, citing Ann Brand and Paul Brinich, 'Behaviour Problems and Mental Health Contacts in Adopted, Foster, and Nonadopted Children', Journal of Child Psychology and Psychiatry, 40, 8 (1999): 1221-1229. (Note that Brand and Brinich's study did take into account the age of placement of adopted children and concluded that it is not a strong predictor of behavioural or emotional problems in these children.) See also L.D. Borders et al., 'Are Adopted Children and Their Parents at Greater Risk of Negative Outcomes?' Family Relations, 47, 3 (1998): 237-241, cited in Sally Haslanger 'Family, Ancestry and Self: What is the Moral Significant of Biological Ties?' Adoption and Culture, 2, 1 (2009): 91-122.

${ }^{37}$ See Blake et al ibid., citing Jésus Palacios and Evan Donaldson, 'Review: Adoption Research: Trends, Topics, Outcomes', International Journal of Behavioral Development, 34, 3 (2010): 270-284. See also Marinus van Ijzendoorn and Femmie Juffer, 'The Emanuel Miller Memorial Lecture 2006: Adoption as Intervention. Meta-analytic evidence for massive catch-up and plasticity in physical, socio-emotional, and cognitive development', Journal of Child Psychology and Psychiatry 47, 12 (2006): 1228-45.

${ }^{38}$ These parents would have to be vetted as well, as would any parents of donorconceived children, single mothers who have no relationship with their child's biological father, etcetera. 
${ }^{39}$ Notice that if such details are enough, then there is no reason to think they could not be available to children born through gestational contract pregnancy, even of the international variety.

40 This appears to be David Velleman's view; see Velleman op. cit. note 34.

${ }^{41}$ One might think that evidence about the psychological well-being of donor-conceived children would be useful here; but unfortunately, the evidence is inconclusive: see Baylis op. cit. note 34, p. 277 . To be sure, there are many reports in the media and elsewhere of donor-conceived people experiencing psychological distress because of missing information about genetic relatives. However, it is simply not known how common this problem is, or will be, among donor-conceived people. It also highly doubtful whether, in our bionormative society, the media would ever give as much attention to "counterstories"- that is, stories told by people who feel no need to know about their genetic relatives — as it does to stories of identity struggle; see again Baylis ibid., p. 278. Dominant society may simply not be interested in hearing about the donor-conceived or adopted child who feels no need for a connection to biological family.

${ }^{42}$ Baylis ibid. She claims that this is true for children born to Indian women in international contract pregnancies. She also explains that India is currently the "destination of choice" for people who want to become parents through this practice. On the bad social circumstances of Indian contract pregnant women, see Amrita Pande's 'Not an 'Angel', Not a 'Whore': Surrogates as 'Dirty' Workers in India', Indian Journal of Gender Studies 16, 2 (2009): 150-154 (cited in Vita Panitch's 'Surrogate Tourism and Reproductive Rights', Hypatia 28, 2 (2013): 274-289).

${ }^{43}$ McLeod and Botterell op. cit. note 2, p. 158. 
${ }^{44}$ Ibid., pp. 160-164.

${ }^{45}$ Ibid., pp. 161-162.

${ }^{46}$ As an anonymous reviewer suggested, one might think that transfers of parental responsibility are importantly different with adoptions, because they do not occur directly between birth parents and adoptive parents. Rather, the state takes responsibility for the child from the birth parents and then transfers it to the adoptive parents. Moreover, given this role, the state is justified in licensing adoptive parents. To respond, it is enough to point out that this is not how it works with all adoptions; in particular, the state does not take the child into its custody with a private adoption.

${ }^{47}$ On the grounds of parenthood, see Tim Bayne and Avery Kolers, 'Parenthood and Procreation' in the Stanford Encyclopedia of Philosophy, 2003, available at http://plato.stanford.edu/archives/spr2003/entries/parenthood/.

${ }^{48}$ On the transferring and delegating of responsibility, see Reuven Brandt's 'Moral Responsibility in Sperm and Ova Donation' (PhD Dissertation, Western University, defended January 2015).

${ }^{49}$ Permanent Bureau, Hague Conference on Private International Law, op. cit. note 6. ${ }^{50}$ We have found that to be true among audiences of our work. For example, one audience member has been Christine Overall, who, in a recent paper, uses a version of the Transfer of Responsibility Argument to support parental licensing for people who wish to become parents through contract pregnancy. See her 'Reproductive 'Surrogacy' and Parental Licensing,' Bioethics, 29, 5 (2015): 353-361.

${ }^{51}$ In addition, if one chooses to license neither prospective parent where only one of them will be genetically related to any resulting child, then one would still be left with 
having to license both parents in cases where neither of them will have this genetic connection.

${ }^{52}$ Carolyn McLeod and Andrew Botterell, 'A Hague Convention on Contract Pregnancy (or 'Surrogacy'): Avoiding Ethical Inconsistencies with the Convention on Adoption', International Journal of Feminist Approaches to Bioethics, 7, 2 (2014): 219-235.

${ }^{53}$ This is not to say that this difference lacks moral significance. To the contrary, it is in our opinion of great moral significance that with contract pregnancy, people go to great lengths to create children when many children in the world need parents. 